\title{
Building-in-Place
}

\author{
RANDALL TEAL
}

Martin Heidegger's Discourse on Thinking lays out a troubling view of the world which holds true today much as it did at the time of his speech:

The world now appears as an object open to the attacks of calculative thought, attacks that nothing is believed able any longer to resist. Nature becomes a gigantic gasoline station, an energy source for modern technology and industry. This relation of man to the world as such, in principle a technical one, developed in the seventeenth century first and only in Europe. It long remained unknown in other continents, and it was altogether alien to former ages and histories. (50)

As an architecture professor in an age of modern technology, I believe it critical that design students cultivate an ability to see more comprehensively and learn to think more meditatively. Developing experience with the nuances of context, culture, and environment must be considered to be the most basic criteria for building in the world, as attunement to these happenings is the basis for preserving and promoting the identity and significance of "place."

An attunement, says Heidegger, "is to be awakened" (The Fundamental Concepts of Metaphysics 63), and William Blattner describes attunement as "a kind of sensibility" that "reveals the imports of things" (Heidegger's Temporal Idealism 65, 48). For the purpose of this discussion I will consider attunement to be one's openness to particular phenomena as revelatory of the qualitative wholeness of a specific situation. Further, that an attunement is to be evidenced through action and involvement rather than explicitly thematized. In general Heidegger's thought 
is important to my work as I see embracing one's immersion in the viscous reality of the world as foundational for the creation of consequential architecture.

In order to elucidate the importance of developing rich relationships with place in architectural design, I draw upon Terrence Malick's film The New World, both in class and in this paper, in part because Malick's vision demonstrates how divergent architectural responses can emerge as a result of differing modes of comportment within a world. This is told in the film through the contrasting stories of the English settlers at Jamestown and the Algonquin tribe known as the Powhatan ("Native Languages of the Americas: Powhatan"), both living and building in the same locale.

The phrase "the new world" has regularly been used in association with the Europeans' "discovery" of the Americas. Malick's film questions this idea of "discovery" by implicitly turning the tables on the habitual conception of this phrase-suggesting that "the new world" is not found in the Americas but in fact is a new worldview brought across the Atlantic by $17^{\text {th }}$ Century Europeans. This is a worldview that is being shaped by the Copernican universe, Newtonian science, and Cartesian Rationalism. In the film, Malick is not shy about highlighting what he presumably believes to be shortcomings of this particular worldview as embodied by the Jamestown settlers, and sets this off against the environmental holism of the Algonquin Natives. ${ }^{1}$

In a search for situated architecture Terrence Malick's work is interesting for several reasons. First is his philosophical training; after studying under Stanley Cavell at Harvard and graduating Phi Beta Kappa, Malick enrolled at Magdalen College, Oxford as a Rhodes Scholar. He developed his doctoral thesis on the concept of "world" in Kierkegaard, Heidegger, and Wittgenstein before a disagreement with his doctoral advisor Gilbert Ryle caused him to leave Oxford. Following this, the reclusive Malick taught philosophy at the Massachusetts Institute of 
Technology for a time and published an English translation of Heidegger's Essence of Reasons. After a brief stint in journalism Malick finally made the transition into filmmaking ("Terrence Malick").

As one might imagine, this background points much of Malick's work toward distinctly philosophical concerns, affording him a unique voice within the world of filmmaking, as described by Hwanhee Lee:

It is often asserted that cinematic images are "signs" (and the films "texts") that are in need of deciphering, according to certain critical traditions and methodologies, that they are presented to us as something to be "understood" (or at least that understanding films, in various ways, requires theories). ${ }^{2}$ Malick's films are in some sense a profound challenge to such notions, as their primary concerns are not plots and characters with complex psychologies, nor some kind of intellectual engagement with ideas. Rather, Malick's films are most distinguished for the primacy and beauty and poetry of their imagery, which reminds the viewers of the fact that the most primal and direct way in which cinema engages its audiences is via the power of images. ("Senses of Cinema: Terrence Malick")

I have found Malick's work helpful in terms of teaching students about building in the environment, in part because envisaging meaningful architecture tends to fall into the same traps as film (i.e., seeking architecture that means something), often becoming dependent on signs and signification instead of settling into more primal and poetic visions activated by the sensuousness of the world. Additionally, Malick's Heideggerian sensibilities, particularly his interest in the notions of phusis and "world," offer an instructive frame from which to view and understand human involvement within our natural and built environments. Similar to these notions, a structural understanding of the temporal wholeness of "place" allows architectural interventions greater opportunity for appropriate response. It is for these reasons that Malick's visions and philosophical reflections carry important lessons for the future of communities, building, and 
sustainable design in general, and are a primary reason for my use of The New World in communicating some of these lessons to beginning architecture students.

In this paper I outline how Malick's film and Heidegger's thought were employed in my introductory architectural design studio to inform a series of progressive design iterations with the intention of fostering sensitive attitudes toward "place", building, and site, ultimately with the hope of discovering more strongly situated architecture. The paper begins with an explication of the two societies as portrayed in The New World, (based on a lecture I presented to the students), then proceeds to describe how some of the resonant images of the film become emblematic of the challenges facing our built environment. The paper then turns toward application in studio, sharing the exercises done with my undergraduate architecture students, and concludes with the difficulties, successes, and future hopes for promoting vitality in our human environments.

\section{Natural World}

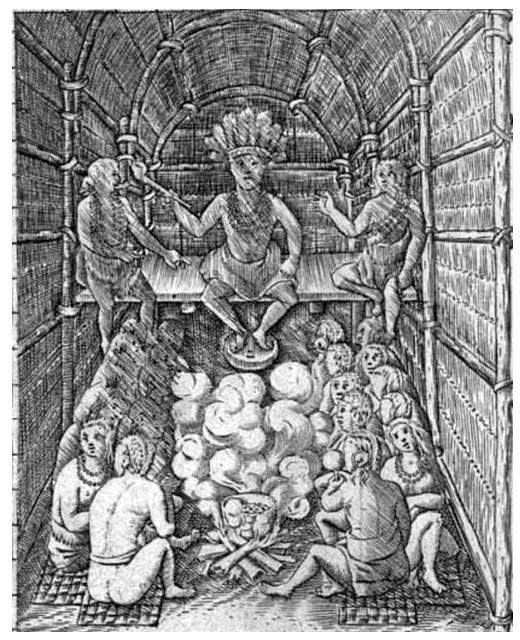

Figure 1. (Smith, Chief Powhatan in a Longhouse at Werowocomoco) 
One of the defining characteristics of the Algonquin Natives, or "Naturals" as Malick refers to them in the film, is their reciprocation with the natural environment, conveyed at the outset of the film with a shot of flowing water and a voice-over saying:

come spirit

help us sing the story of our land

you are the mother

we a field of corn

we rise from out of the soul of you.

Throughout the film the Naturals exhibit practices that reflect and build upon these opening lines. Their movements appear to demonstrate their primordial spirit, their dress reveals response to climate and environment; they are infinitely open and inquisitive; communication is for them both bodily and tactile; and building and work assume a manner that is inextricable from the land they inhabit. For them all appears interrelated and they receive and activate meaning through attentiveness to their world. "I will find joy in all I see," says Pocahontas. With this statement we see a kind of receptivity that invites the world to penetrate, affecting practices, behaviors, and community.

This receptivity is made manifest in the Naturals' settlement, which reveals itself as a topological arrangement, loosely bound and woven through the trees. Further, their method of building provides a more flexible means to activate specific locations nested within this region and to accommodate varied activities such as warrior training, shell sorting, dwelling, and cooking. The Naturals' recognition of potentialities within their forest home appears to be similar to the kind of sensitivity Christian Norberg-Schulz's essay "The Phenomenon of Place" speaks of. Norberg-Schulz explains,

[Man] wants to make the natural structure more precise. That is, he wants to visualize his "understanding" of nature, "expressing" the existential foothold he has gained. To achieve this, he builds what he has seen. Where nature suggests a delimited space he 
builds an enclosure; where nature appears "centralized," he erects a Mal; where nature indicates a direction, he makes a path. (421)

In a similar fashion the Naturals' constructions are sprinkled throughout the clearings in the trees giving the impression that the forest and the settlement somehow grew from the same source. In this way the village springs from the already rich spatiality and builds up, amplifying and articulating the "natural structure" via material, function, and light.

All aspects of tribal life are hung from this articulated structure and are centered on the place of the village proper. Tasks and practices are highly ritualized and there is a sense that, in terms of setting up this life, the Naturals possess an understanding which affords them a precise response to specifically what is given. One area where this is exhibited is in their sapling and reed-skin dwellings (Figure 1) which, like their clothing, seem to be exactly durable enough to serve their needs for home and shelter without excess. These structures are multiple in their engagements with life and nature; the historical record tells us that the saplings were stuck into the ground, bent over and tied at the top with strong roots, and then covered with tree bark or mats made from woven reeds. Furthermore, a hole was left in the top of the house so that a fire could remain burning for warmth and to ward off evil spirits. Instead of doors, the houses employed hanging mats that could be opened completely for ventilation when the weather was hot (Burke, McKiernan and Shaw, The Indian Village). Structures that were any more substantial would have not only wasted resources but also created unnecessary separations between the people and their surroundings.

With little question as to his personal proclivities, Malick amplifies the lushness of this intermingling and the beauty that emerges through this exchange, and in so doing highlights the Naturals' attunement to all that presences within this land. 


\section{Instrumental World}

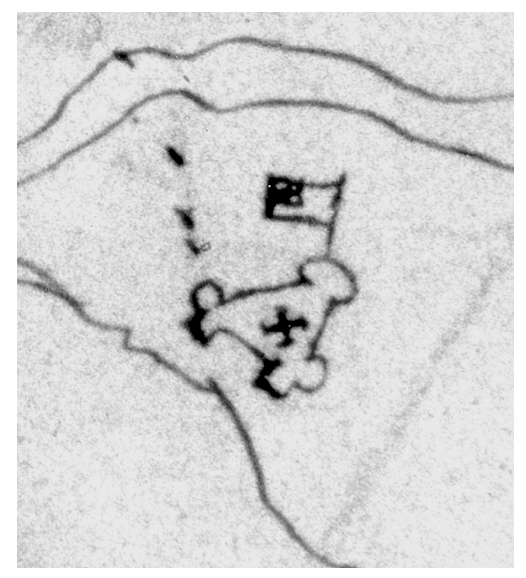

Figure 2. (Smith, Sketch of the Jamestown Settlement)

As opposed to the listening Naturals, Malick presents the English as always looking. They are preoccupied by goals and the things they will be doing in a way that is so purely instrumental they are generally unable to connect with anything in their present surroundings as intrinsically meaningful. Instead of "being-there," participating with phenomena as it wells up before them, we find the English mostly "being-away"; that is, they are preoccupied by their own scheming, with their attention seemingly everywhere except their current involvements. ${ }^{3}$

These settlers and their Cartesian worldview arrive in ships that bob in the harbor like displaced corks, a contrasting scene to that of the witnessing natives, who scuttle about the trees and underbrush of the shoreline like inquisitive animals. Despite their animal-like qualities and an uncanny ability to seamlessly integrate themselves into the ecology, we do not find the Naturals "captivated" like animals, as we have already seen their ability to comport themselves toward things within their world as such. Rather, as the story unfolds, it begins to appear that the "civilized" English are ultimately those who behave in the world-poor, instinctually driven manner of animals, which is to say that that their way of being is not self-interpreting or world- 
disclosing but rather is of a behavioral character that is fundamentally self-focused (Heidegger, The Fundamental Concepts of Metaphysics 239). Further, their actions and attitudes towards this place exhibit many of the eliminative and devouring behaviors that Heidegger attributes to animals (250). Perhaps the English are Malick's ode to the rational animal, as they come ashore wearing ungainly suits of armor looking at all aspects of their new environment with a rigid and measured opportunism. This disposition appears puzzling to the Naturals, since it is exactly opposite to their manner of unqualified participation. This strange behavior even prompts one of the Naturals to knock his fist inquisitively on a sentry's metal shell, seeming to wonder whether the Englishman might in fact just be some sort of large insect. The English settlers, like the moth which "flies straight into the light and is destroyed in so doing," (251) are drawn with certainty into North America's glowing bounty, neglecting the daily workings of their lives, thus marking the trajectory for our own untimely demise. ${ }^{4}$ The English, tethered in memory and spirit to their distant native soil, lack wonder for their new world, which ensures that there will be very little cross-pollination with their Jamestown locale. This basic inability to engage the new environment with genuine sophistication is indicative of a still-prevalent attitude which only promises a final plunge into the flame.

The Jamestown settlement itself is the harbinger of this self-immolation. Conceived in a way diametrically opposed to the Naturals' village, rather than being topological, the settlement takes on a distinctly geometric form (Figure 2) and disregards the surrounding woodland as it is founded in a barren clearing. The film's depiction is true to the actual Jamestown settlement and the emphasis on predetermined form is consistent with the emerging seventeenth-century worldview, which was coming to be more and more captivated by mathematical geometrics. Alberto Perez-Gomez describes the origins of this particular fondness for geometry and its 
perpetuation in Architecture and the Crisis of Modern Science, where he describes how prevailing rationalism created a focus on the numerical aspects of geometry and with that focus "geometrical forms lost their cosmological reverberations" and "were uprooted from the Lebenswelt and their traditional symbolic horizon," transforming architecture into "signs of technological values." In the end he believes this tendency toward rationalistic geometry has left us a legacy of building devoid of significance that "speaks only to technological progress, not to the world of man" (311).

The English focus on technological progress leaves them unmoved by the lush ecological character of the place as Captain Newport commands his men, "In the morning, we will chop down every tree within half a mile of the moorage, and use the straightest limbs to erect a line of watchtowers and to build our fort." The boundary that results from this command becomes relentlessly present, creating an impenetrable wall between the structures of the village and the natural environment around them. Inside the palisades the buildings appear as overbuilt English vernacular with interstitial spaces that might be best characterized as muddy, amorphous noman's-lands (both functionally and spatially). Premeditation and systemization nullify possibilities for experiential connections, leaving the place-specific phenomena of Jamestown to lie dormant, unenhanced, and uninfluential.

As portrayed by Malick, the English settlement at Jamestown appears to be the apotheosis of de-worlded Cartesianism and although certainly given a fine point in the film, it still remains a lucid demonstration of the limitations of this brand of world-poor rationalism. Jamestown's lack of character and one-dimensional interface with this location are tied directly to a world that is understood to be merely a container for resources. The near total failure stemming from this outlook reinforces the notion that one must first be open, and prepared to 
respond. In this way experience can become meaningful and allow the interdependent nature of things to be revealed.

\section{Architectural World}

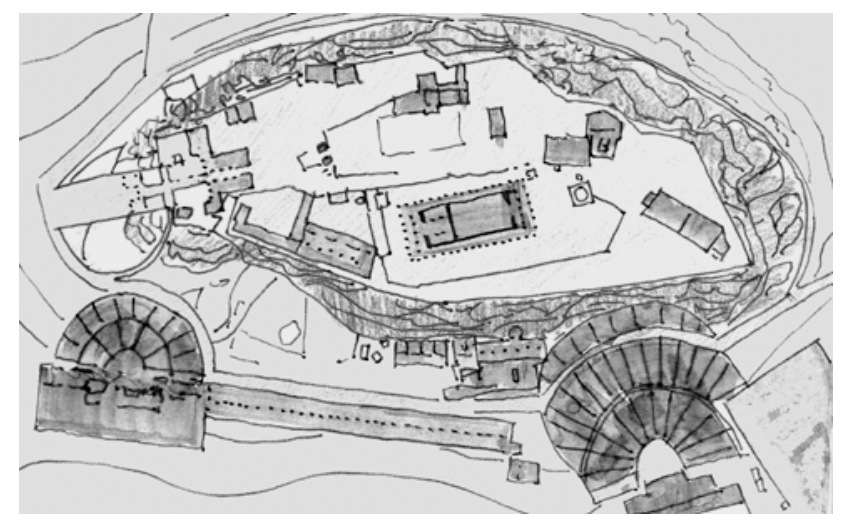

Figure 3. Acropolis Plan View

The contemporary built environment abounds with examples of both of the worldviews presented by Malick in the film. Unfortunately there seems to be an ever-increasing prevalence of the type of orientation toward building as demonstrated by the English. As a result we come to find our built environment blighted by structures constructed without particular attention to the unique circumstances in which every building ultimately finds itself. Contrary to this sort of unharmonious intervention, the creation of architecture requires strong relations to context and the capacity to be affected by the spirit of a place.

The beginning of this conflict between worldviews in architecture rises out of the scientific revolutions of Newton and Galileo. As universal laws begin to question the relevance, significance, and truth of specificity and difference in the environment, the universalizing push raises the question as to the right way to build which is presumed to have theoretical 
underpinnings. This in turn makes what had for the most part been situated in tradition, location, and culture open to rationalistic debate and generalizing absolutism (Perez-Gomez 10-11).

Location remains one aspect of architecture that initially resists leveling since the beginning of any design project invariably requires ascertaining the characteristics of the site. Unfortunately my experience has been that typical architectural site analysis still tends toward a brand of rationalism whereby properties and data are either generalized outright, or collected and cataloged meticulously as a series of discrete phenomena to be later re-assimilated by analysis. Heidegger describes the problem with this type of purely cognitive engagement in Being and Time saying, "When space is discovered non-circumspectively by just looking at it, the environmental regions get neutralized to pure dimensions. Places ... get reduced to a multiplicity of positions for random Things" (147). In other words, non-circumspective discovery relies on analysis which in turn degrades "involvement-character" into raw facts and makes relational significance impossible since things are deprived of their "worldhood" (147). In architecture this type of seeing simply leaves too much out. The reduction of a situation into either a collection of data or a simplistic generalization effectively flattens a location's phenomenal significance and muffles the resonant voice of place. For example, the Acropolis (Figure 3) is often represented by the lone image of the Parthenon, which degrades our understanding from a complex spatial arrangement composed of a number of buildings to sceneographic Classicism. In actuality the Acropolis is both sensitive and deliberate in its relation to the site as its various structures are thoughtfully located within the given locale. The resulting composition is much more striking when understood in its entirety and serves in part to make the Acropolis the specific "place" that it is. Heidegger makes similar observations as to the inseparability of the bridge from its locale in his essay "Building Dwelling Thinking," suggesting that, "It does not connect the banks that are 
already there. The banks emerge as banks as the bridge crosses the stream... The bridge gathers the earth as landscape around the stream" (150). Heidegger's elegant description of the bridge reflects my belief in the preeminence of "place" and the role that dialogue should play in the creation of architecture —or, as he says, "this speaking that listens and accepts is responding" (Heidegger, "Language" 206). So too must architectural response arise from attitudes and practices that are first trained to speak by listening.

\section{Pedagogical World}

Terrence Malick's film might be seen as delivering its message with a vehicle similar to the technique suggested by Heidegger early in Being and Time:

To orient the analysis of Dasein towards the "life of primitive peoples" can have positive significance as a method because "primitive phenomena" are often less concealed and less complicated by extensive self-interpretation on the part of the Dasein in question. Primitive Dasein often speaks to us more directly in terms of a primordial absorption in "phenomena" (taken in a pre-phenomenological sense). A way of conceiving things which seems, perhaps rather clumsy and crude from our standpoint, can be positively helpful in bringing out the ontological structure of phenomena in a genuine way. (76)

The "positive significance" for my students in bringing these examples back into the classroom is that, by way of Malick's portrait, there lie instructive cues as to how we might regard building in the environment, and what we might then do to apply these revelations in a search for more responsive constructions.

In architecture I am interested in a kind of openness, one that endeavors to correct an overreliance on rational thought, one that allows awareness and understanding by way of experience and participation. This notion seems aligned with what William Blattner believes to be one of the foundations of Being and Time where he says, 
Heidegger offers an alternative description of experience. He argues that our fundamental experience of the world is one of familiarity... This is to say both that familiarity is more basic than cognition, and that cognition is not self-sufficient, but rather a derivative form of familiarity. (Heidegger's Being and Time 12,46)

Blattner's point is extremely relevant to those engaged in the process of designing buildings, as the primary commitment of architecture should stem directly from the affectedness generated by experience within a particular place. This stands in opposition to the frequently practiced analytic beginnings such as site dimensioning, sun angle measurement, traffic flow assessment, etc., which although certainly part of the story can easily masquerade as universal truths, which in turn cover up a lack of familiarity with relational significance. Just as one might be best advised to not buy clothes for another based on measurements alone, architecture holds even stronger need of appropriate affect. With this in mind perhaps we can move the practice of architecture away from the single-minded intellectualism that has ventured to seduce it, beginning in the seventeenth century, crystallized in J.N.L. Durand's 1802 Art and Science of Architecture, and carried on through International Style Modernism into much contemporary practice (Perez-Gomez).

Do not be misled, as there is considerable occasion for intellectual focus in architecture. However, the penchant for intellectualism makes it even more imperative to bring students into direct contact with experience early and often. Without this emphasis, the intellectual has a way of railroading the primacy of experience, in large part because it is knowable and therefore safe. Yet this safety is precisely the danger to real progress, as Heidegger says in, "What are Poets For?": "In an age of the world's night, the abyss of the world must be experienced and endured. But for this it is necessary that there be those who reach into the abyss" (90). 
Reaching into the abyss in design, which might be thought of as living the questions of the blank page, is enlivened by connections with, and spatial elaboration of experience, by way of the action of making. This gives architecture the grounding to establish meaningful priorities and hierarchies from which finished works may gradually materialize. This process requires a staying with ambiguity and a timely leap into the heart of the unknown when opportunity is seen to shine. In this way architecture might be best understood as arising from an attunement with people, place, and activity, fomented by the creative process, emerging as forms reflective of such awakened vitality. Heidegger claims in "Poetically Man Dwells": "Man is capable of such building only if he already builds in the sense of the poetic taking of measure" (225). In the process of design and building in the environment, poetic taking of measure is architecture, which happens when skillful response evolves through a practice of making.

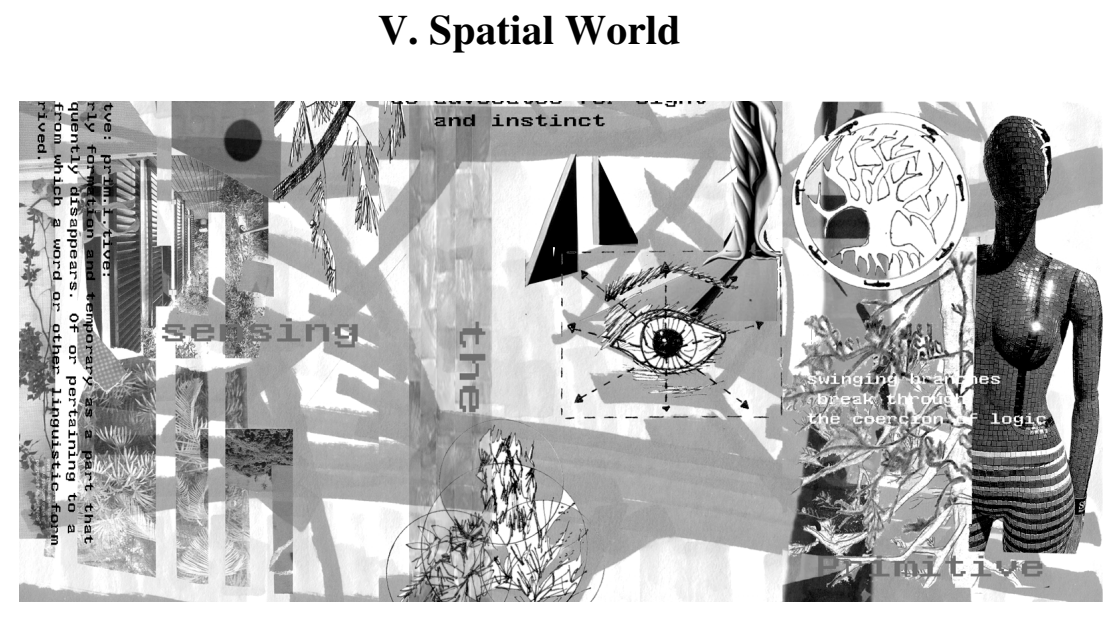

Figure 4. Lauren Pokorny

Throughout our existence we are subject to a multitude of shifting worlds that ask that we let one go so that we might open onto a new situation. For example, even the daily cycle between 
home and school requires one to be drawn completely into each respective realm if one is to be successful. If one is not able to shift, then one is left thinking about dinner while one should be teaching architecture!

Extend this example further to the making of architecture and perhaps we begin to see why so many half-cocked assemblages populate our cities. The journey one must travel to bridge the unfamiliarity of the new, with a familiarity that is steeped in the actuality and nuance of the fresh situation, is arduous. With this in mind it becomes easy to grasp why one might imagine a situation as being more similar to past encounter than it actually is. In this way one refuses to "reach into the abyss," choosing the ease of sameness over the appropriateness of true response. Unfortunately, quality building demands the ability to respond, which is why this must be taught in architectural education.

My introductory architectural design studios run counter to the fragmenting proclivities of science and empirical data collection, as I direct students to first engage the situated, hierarchical, and relational aspects of "place." During the opening week of the studio class in question, students were challenged with coming to know a site through a process of active reciprocation informed by Heidegger's notion of "world." "World" for the students came to mean a wooded hillside within the confines of our campus which was the site for a small study hall design project.

Conveniently, our “design world” was about a hundred yards away from students' desks. However, despite one student's statement that "having a site we could visit was a wonderful tool," past experience has shown that proximity is never a guarantee for increased involvement or more resonant attunement. Students will tend to walk around the site like bad tourists, snapping photos and taking in only the most obvious and ubiquitous elements, atomizing and 
cataloging as they go. This predilection is evidenced in another admission at the end of the semester: "I was surprised to be at the site so much... I thought architecture was mostly done sitting at a desk."

In order to remedy this misconception, my first task was simple enough-have the students visit this place many times. I accomplished this directive by devising an activity that necessarily required considerable time on site. The exercise was called "Site 100" and it asked students, over the course of three weeks, to encounter this place on 100 occasions and produce a physical trace of each encounter. This iterative process was intended to shift the students from a mere looking for predetermined information to a kind of partaking of the site, made manifest through a variety of material processes. In other words, students were to learn this "place" by performing activities that responded to, engaged, and interpreted the phenomena. In so doing, they would arrive at 100 artifacts of interaction.

Since drawing is an excellent form of active meditation, eighty of these interactions were to involve drawing with different media in varied approaches, including pen, pencil, charcoal, colored pencil, contour drawings, non-dominant hand drawings, time-limited drawings, gestural drawings. Ten traces were required to take the form of some sort of collage or assembly and the final ten needed to be done in writing. In undertaking this activity students were asked to discover and engage such things as sounds, smells, color, texture, activity, and mood. Upon completion of all one hundred encounters, they were asked to edit and synthesize their process into one work that communicated the complexity of the place as holistically as possible, presented on three 11"x 17" panels.

Establishing familiarity with this place by way of direct coping appeared to develop sophistication in student understanding. Contrary to the outcomes of typical site observations, 
which might have produced such obvious reports as: "the site is a group of trees in the middle of campus," or "an impromptu path between buildings," students arrived at characterizations like: a power holding open a hidden space of nature; a secret; a metaphoric place of memory; a dance of the natural and human-made; primal complexity (Figure 4); nature interrupted; an aesthetically undesirable but overlooked safe haven in need of cultivation. This was certainly an encouraging beginning to the project, one that I hoped would be further teased out and augmented as the design progressed. The difficulty now arose of how to keep this environment vital and student revelations fresh as more information became a concern and new tasks needed to be accomplished.

\section{A World of Withholding}

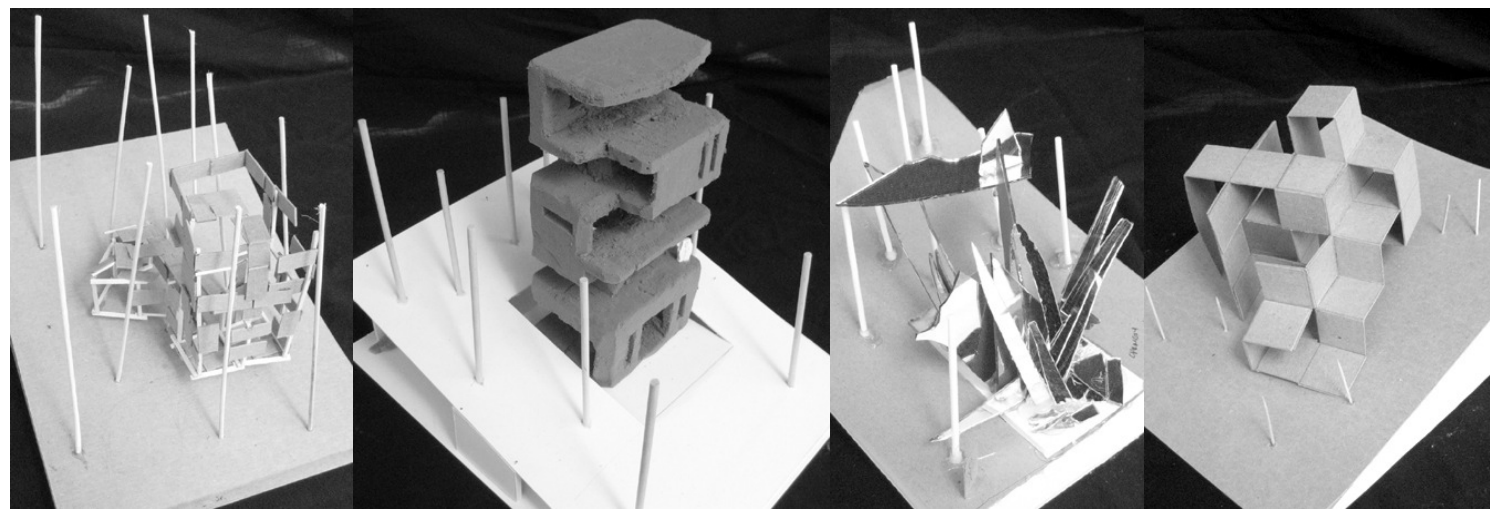

Figure 5. Ofelio Resendiz, Katherine Olin, Carmen McIntosh, Eric Whitney

If one is to move beyond salvaging old answers and applying them to new questions, the new questions must be raised into visibility. Raising the questions of the site into visibility came by way of student graphic and verbal presentations. Thrown directly into the phenomena, each student showed themselves to be aligned with the site in a particular way that brought forth a 
vital identity. Now in order to steer students away from generalizing their understandings it became necessary to initiate a series of small interactive steps which would allow a cohesive building design to emerge gradually.

In order to divert anticipatory thinking, the introduction of a limited framework for spatial response allowed scale and measure to be added to the site relationship without having students think "building." A series of limitations were laid out with key pieces of information pending, so that not only was a real architectural program (consisting of set square footages of designated spaces) withheld, but the students were offered particular focused strategies that directed initial architectural incursions into four distinct modes of materialization.

First students made a series of scale models of the site, capturing the essential spatial qualities of this sloping wooded parcel. Then they were asked for "spatial interventions" in four different ways: additively, subtractively, by deconstructing an object, and with an infinite strip (Figure 5). The idea was to prevent students from premeditating their buildings, and this was regulated by way of these restricted avenues of approach. Further, these parameters reduced the need for cognitive processes and thus offered greater opportunities for intuitive response. In a sense, this was an exercise in performative familiarity, establishing understandings of the building and investigating the actualities of the site without thinking about the building or the site. As these examinations began to take hold, a rich vocabulary of spatial possibilities developed and architecture slowly emerged—almost on its own.

As the project went on, students used the various functional criteria to chisel away at this raw material and allow the building to, in effect, be born out of their interactive involvements with the site. The goal of this process might be summed up by Heidegger's observation in his Introduction to Metaphysics: 
[W]e do not repeat a beginning by reducing it to something past and now known, which need merely be imitated; no, the beginning must be begun again, more radically, with all the strangeness, darkness, insecurity that attend to a true beginning. (39)

Negotiating the darkness of beginning requires daring. In addressing the difficulty of giving oneself over to this way of designing, one student confessed, "it all got better three weeks ago when I decided to draw more and cry less." It is this sort of courage that is necessary for there to be real progress in the way we build.

\section{Studying World}

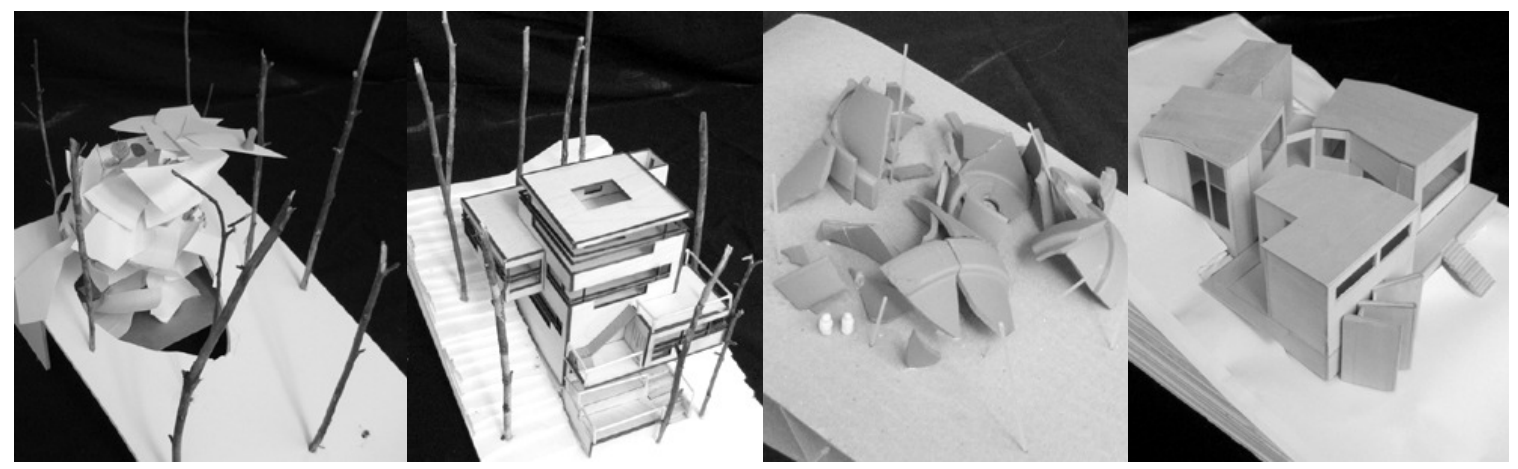

Figure 6. Before/after Emily Eixenberger; Before/after Robert Carbaugh

In the end students had to be reminded on several occasions about their past travails, as they had an uncanny ability to forget their discoveries at the most inopportune moments. This is interesting as it seems to indicate the double edge of familiarity. In this case students had spent such a great deal of time roaming the site and making models; yet as new tasks surfaced, past interaction got packed up like the proverbial summer home. The students' prodigious talent for forgetting brings us face to face with our overwhelming leaning toward habituation and is a reminder as to the relentlessness with which we must re-cycle matters if they are to be of importance. This struggle with familiarity nonetheless had a positive side: a simple reminder was 
all that was required by many students to put them back on track, and much previously gleaned understanding, despite being buried at moments, was still very much available to the students, who were still generally setting it into action in their projects (Figure 6).

A strong group of final projects seemed to not only show great progress, but the beginnings of some soundly contextual architecture as well. In questioning students after the semester, many agreed that the incremental, limited responses they were asked to make, although confusing at first, actually facilitated architectural breakthroughs. One said "the models were a good way to develop multiple ideas and open my mind to what was possible"; another attested, "the process helped to break down preconceptions... it helped to create something that was right," and finally another claimed, "it was difficult because it was so easy. You just have to learn to let yourself go." This last comment reminded me of a remark Heidegger makes in his essay "Language," speaking of a poem by Georg Trakl. Heidegger says, "[w]ho the author is remains unimportant here, as with every masterful poem. The mastery consists precisely in this, that the poem can deny the poet's person and name" (193). I would venture to say the case of masterful architecture should be no different. 


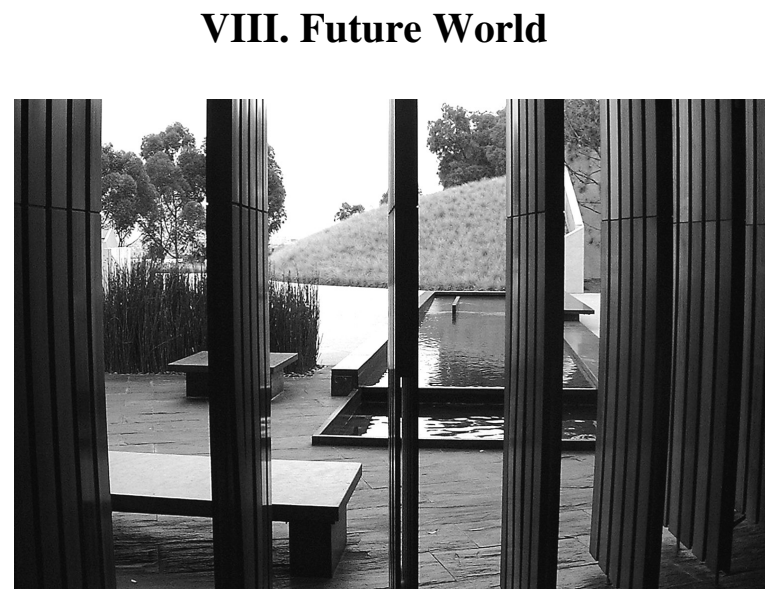

Figure 7. Neurosciences Institute by Tod Williams and Billie Tsien, La Jolla (CA)

The greatest danger for the future of architecture is for design to spiral into a quest for highest yield or maximum efficiency, and to be driven primarily by profit, in other words the very same style of coping demonstrated by the English in Terrence Malick's film. An overarching conception of world as that of a collection of exploitable resources eliminates "ends as ends," and "life" comes to be understood as something to be experienced later on. With this view it follows that significance and meaning eventually become impossible.

A similar loss of ends currently shows itself as the challenging that is evident in many aspects of our lives, including commuter culture, the search for social prestige, and planned obsolescence in our market economies. This sort of enframing colors architecture as well and reveals itself in part via the box stores and tract development that litter our planet. Given the complex set of concerns that must be allowed to influence the existence of a building, an architecture whose primary aim is profit or efficiency can never properly be called architecture.

Instead of reading The New World as an advertisement for a return to primitivism, perhaps it can be best seen as a reminder of the importance of experience and involvement in 
revealing of the soul of a place. Malick's film provides an interesting study of the extreme qualitative differences that can arise in the same location with the same resources. In the film, one society is successful in activating its environment through its employment of situated tools, while the other destroys the environment and itself by the instrumental use of technology. This simple juxtaposition suggests that it is not technology itself that is the problem; rather it is one's specific attunement that becomes critical to success or failure. To this end, Heidegger calls out our responsibility to the proper implementation of our paraphernalia:

I would call this comportment toward technology which expresses "yes" and at the same time "no," by an old word, releasement (Gelassenheit) toward things... I call the comportment which enables us to keep open to the meaning hidden in technology, openness to the mystery. (Discourse on Thinking 54, 55)

Thinking about architecture from this perspective, one might begin to see that closedness to environments brokers banal development. Rather than singular objects perhaps buildings might be better conceived as being a "there," presencing as the environment itself. Tod Williams and Billie Tsien's Neurosciences Institute in La Jolla, California (Figure 7), provides one example of how this might look; the building is so skillfully unfolded and integrated into a built landscape that photos cannot effectively communicate the potent experience of this place.

As for becoming familiar with complexity in design education, my students' experience with Heidegger and the associated process seemed fruitful. Although the final work was inconsistent (a mix to be expected in introductory studios) the majority of students appeared to move beyond the typical belief that visiting the site, taking some photos, and making a few sketches constitutes a real grasp of environmentality and this, in most cases, had positive influences on final projects. 
In an age where sensitivity toward the environment is more critical than ever, richer definitions of sustainability must be sought. Ecological design must learn to integrate scientific approaches in order to address building performance, all the while cultivating concernful awareness, remembering that it is essential to sustain meaning and significance in the environment as well. Without an ability to open and listen, there can be no speaking, no world, and no places. My hope is that exercises in phenomenology and hermeneutics might cause designers to delve more deeply into the situations where they intend to intervene, building stronger connections to nature, context, and place, trusting that these attitudes will propel us toward a more sustainable sustainability.

\section{Notes}

1 There is poetic license in both the film itself as well as my interpretation of it, since the repercussions of such philosophic and scientific events would certainly have had a lag time before they actually took hold. My position is simply that Malick seems to be using the emerging mood of the time and the rough correspondence of dates as a vehicle for the argument made by the film.

${ }^{2}$ For an illuminating paper on this tendency, see Karen Hanson, "Provocations and Justifications of Film."

3 Heidegger says that "being-away pertains to the essence of being-there," that is, it is a characteristic of Dasein, and describes the phenomenon of being-away as such: "How often it happens, in a conversation among a group of people, that we are 'not there', how often we find that we were absent, albeit without having fallen asleep. This not-being-there, this being-away, has nothing at all to do with consciousness or unconsciousness in the usual sense. On the contrary, this not-being-there can be highly conscious. In such being absent we are precisely concerned with ourselves, or with something else" (Heidegger, The Fundamental Concepts of Metaphysics 63).

${ }^{4}$ The English of course eventually establish their colonies in Virginia and throughout North America so when I speak of demise I mean to suggest their initial attempts at Jamestown are indicative of the decline into technological thinking. 


\section{Works Cited}

Blattner, William. Heidegger's Being and Time. London/New York: Continuum, 2006.

—. Heidegger's Temporal Idealism. Cambridge: Cambridge University Press, 1999.

Burke, Meghan, Brooke McKiernan, and Kathryn Shaw. "The Indian Village". Richmond, 19982206. December 2, 2007. (http://oncampus.richmond.edu/academics/education/projects/ webunits/vahistory/village.html)

Descartes, Rene. Descartes: The World: And Other Writings. Ed. Stephen Gaukroger. 1998. (http://ida.lib.uidaho.edu:5821/lib/uidaho/Doc?id=2000793)

Hanson, Karen. "Provocations and Justifications of Film." Philosophy and Film. Ed. Cynthia A. Freeland and Thomas E. Wartenberg. New York: Routledge, 1995. 33-48.

Heidegger, Martin. Being and Time. Trans. John Macquarrie and Edward Robinson. San Francisco: Harper and Row, 1962.

—. "Building Dwelling Thinking." Trans. Albert Hofstadter. Poetry, Language, Thought. New York: Harper \& Row, 1971. 141-59.

-. Discourse on Thinking. Trans. John M. Anderson and E. Hans Freund. New York: Harper \& Row, 1966.

-. The Fundamental Concepts of Metaphysics: World, Finitude, Solitude. Trans. William McNeill and Nicholas Walker. Bloomington/Indianapolis: Indiana University Press, 1995.

- An Introduction to Metaphysics. Trans. Ralph Manheim. New Haven and London: Yale University Press, 1959.

—. "Language." Trans. Albert Hofstadter. Poetry, Language, Thought. New York: Harper \& Row, 1971. 188-208.

—. "...Poetically Man Dwells..." Trans. Albert Hofstadter. Poetry, Language, Thought. New York: Harper \& Row, 1971. 211-27.

—. "The Question Concerning Technology." Trans. William Lovitt. The Question Concerning Technology and Other Essays. New York: Harper \& Row, 1977. 3-35.

—. "What Are Poets For?" Trans. Albert Hofstadter. Poetry, Language, Thought. New York: Harper \& Row, 1971. 87-139.

Lee, Hwanhee. "Senses of Cinema: Terrence Malick." Senses of Cinema. November 2002. January 12, 2008. (http://www.sensesofcinema.com/contents/directors/02/malick.html) 
Malick, Terrence. Writer \& Director. The New World. 2006. USA: New Line Home Video. "Native Languages of the Americas: Powhatan," Native Languages of the Americas: Preserving and promoting American Indian languages. 1998-2007. January 15, 2008. (http://www.native-languages.org/powhatan.htm)

Norberg-Schulz, Christian. "The Phenomenon of Place." Theorizing a New Agenda for Architecture. Ed. Kate Nesbitt. New York: Princeton Architectural Press, 1996. 414-428.

Perez-Gomez, Alberto. Architecture and the Crisis of Modern Science. Cambridge: MIT Press, 1983.

Pokorny, Lauren. "Site 100." 2007.

Smith, John. Chief Powhatan in a Longhouse at Werowocomoco. 1612.

—. Sketch of the Jamestown Settlement. 1608.

Teal, Randall. "Drawing: Acropolis Plan View." 2007. Based on Drawing by J. Travlos 1978. Accessed December 2007 at (http://www.goddess-athena.org/Museum/Temples/Parthenon/Acropolis_plan.html)

—. All photos of student work. 2007.

—. "Neurosciences Institute". 2003.

"Terrence Malick." Wikipedia: The Free Encyclopedia. January 8, 2008. January 14, 2008. (http://en.wikipedia.org/wiki/Terrence_Malick) 